\title{
Pathological Migration Associated with Loss Of Posterior Teeth
}

Research Article

Harrita. $\mathrm{S}^{1}$, Suresh. $\mathrm{V}^{2 *}$, Senthil Murugan. $\mathrm{P}^{3}$

${ }^{1}$ Saveetha Dental College and Hospitals, Saveetha Institute of Medical and Technical Sciences, Saveetha University, Chennai, India.

${ }^{2}$ Reader, Department of Prosthodontics, Saveetha Dental College and Hospitals, Saveetha Institute of Medical and Technical Sciences, Saveetha University, Chennai, 600077, India.

${ }^{3}$ Associate professor, Department of Oral and Maxillofacial Surgery, Saveetha Dental College and Hospitals, Saveetha Institute of Medical and Technical Sciences, Saveetha University, Chennai, 600077, India.

\section{Abstract}

Many evidences are available on tooth positional changes following loss of an adjacent tooth but only few studies are available on the investigation of tooth, positional changes adjacent to the site of posterior tooth loss attempts to provide increased understanding of magnitude direction and associated features that may be helpful in decision making and treatment planning.In case of vertical positional changes such as supra eruption, The anatomy of the supraerupted tooth may have prognostic implications where active eruption is encountered. In teeth with root furcation, these may become exposed, and create plaque traps which may compromise the periodontal health. Exposure to the root surface may also precipitate pulpal sensitivity, root caries and create aesthetic compromise. In case of horizontal positional changes such as migration, tipping, rotation of adjacent tooth leads to reduction in space or interocclusal clearance for placement of a replacement tooth, this leads to angulation of abutment teeth, Changes in occlusal loading, Poor embrasure contour around pontic. Obviously, change in the position of the tooth crown is clinically visible, but the changes in position of the root and therefore the apex may be of clinical relevance. Tipping may increase the proximity of roots of adjacent teeth and other anatomical structures. Changes in root position may also affect the interdental space available for implant placement and make it more difficult owing to changes in relative anatomical position. Thus the aim of the study is to evaluate the pathological changes associated with posterior tooth loss.

A retrospective study done under university setup, where 86000 case sheets were reviewed from the record management system of the college, out of which 419 case sheets satisfied the inclusion criteria of this study. The collected data was compiled and statistically analysed using SPSS software version 23.0. From this study, In patients who needed localised plane correction, $14.32 \%$ had supra eruption, $12.41 \%$ had mobility, $0.24 \%$ had attrition and $0.24 \%$ had proclination of remaining teeth and in patients who needed generalised plane correction, $52.51 \%$ had supra eruption, $14.80 \%$ had mobility, $5.49 \%$ had attrition of remaining teeth for which the $\mathrm{P}$ value $(0.000)$ was found to be statistically significant $(<0.05)$. Thus there is significant association Occlusal correction and remaining teeth condition. In 18 to 30 years, $0.24 \%$ had mobility, $4.53 \%$ had supra eruption, $0.24 \%$ had proclination. In 31 to 50 years $12.41 \%$ had mobility, $28.40 \%$ had supra eruption, $1.43 \%$ had attrition. In 51 years and above $14.56 \%$ had mobility, $33.89 \%$ had supra eruption, $4.30 \%$ had attrition, this was the statistically significant with $\mathrm{P}$ value lesser than 0.05 . From this study it can be concluded that ACP PDI class III condition creates spatial changes in the remaining natural teeth. Supra eruption as the most common changes to occur and such individuals required generalisedocclusal plane correction indicating its just not one tooth in the line for supraeruption correction but multiple teeth. This shows the long term negligence of patients in replacement of missing teeth, the importance of teeth replacement and its associated effect on other masticatory systems are lacking among the population studied.

Keywords: ACP PDI; Migration; Mobility; Posterior Tooth Loss; Supra Eruption.

\section{*Corresponding Author}

Suresh.V,

Reader, Department of Prosthodontics, Saveetha Dental College and Hospitals, Saveetha Institute of Medical and Technical Sciences, Saveetha University, Chennai, 600077, India. Tel: +919543192858

E-mail: suresh@saveetha.com

Received: September 06, 2020

Accepted: October 09,2020

Published: October 24, 2020

Citation: Harrita. S, Suresh. V, Senthil Murugan. P. Pathological Migration Associated with Loss Of Posterior Teeth. Int J Dentistry Oral Sci. 2020;7(10):903-907. doi: http://dx.doi. org/10.19070/2377-8075-20000179

Copyright: Suresh. $\mathbf{V}^{\circ} 2020$. This is an open-access article distributed under the terms of the Creative Commons Attribution License, which permits unrestricted use, distribution and reproduction in any medium, provided the original author and source are credited. 


\section{Introduction}

Shortened dental arches consisting of anterior and premolar teeth have been shown to meet oral functional demands however the occlusion stability may be at risk as a result of tooth migration [1]. Movement of teeth adjacent to our opposing edentulous space may often complicate planned prosthetic restoration or create a closer look interference $[2,3]$. The stability of dental arches in humans has been the subject of several investigations. Movement of teeth adjacent to, or opposing edentulous spaces may often complicate planned prosthetic restorations or create occlusal interference. Some theories support the concept that dental supraeruption is a continuous process compensating for tooth wear. Nevertheless, there is no adequate scientific documentation regarding dental arch stability following tooth loss. There is a general belief among dentists that teeth without antagonists are most likely to be supraerupted [4]. The main positional change to be expected in unopposed teeth, retained root stump and carious teeth is supra eruption. If we replace the edentulous area with the prosthesis, without correcting the supra-erupted teeth, it may lead to inefficiency in the masticatory function due to improper distribution of masticatory force, deviation in the mandibular movement and problems in the Temporomandibular Joint [5]. Muller De Van stated that "the preservation of that which remains is of utmost importance and not the meticulous replacement of that which has been lost". This statement holds true in case of management of supraerupted teeth. Because invariably the moment we see a small amount of supra-eruption, we still go ahead with replacement of the opposing edentulous area with an RPD or FPD which leads to occlusal disharmony and consequently TMJ Disorders. When the dentoalveolar extrusion is not too severe, it is possible to recapture space by performing Coronoplasty or intentional endodontic treatment of the supra-erupted teeth.6 A survey by military dentists concluded that mesial inclination of teeth distal to an edentulous area was not inevitable but rather seem to depend on the age tooth loss had occurred but rather proofs were given by Dental casts and radiograph of patients with unopposed molars.

A retrospective study compared bitewing radiographs in patients of 24 to 90 years of age for changes in position and periodontal health of teeth next to edentulous space [7]. Investigation with Unopposed posterior teeth presented with some form of supraeruption and teeth adjacent to extraction sites presented with some form of tripping or rotation [8, 9]. A recent study showed deviations five years after adjacent tooth loss [10]. There is a possible correlation between the age and time of tooth loss and subsequent dental arch stability, It would be helpful to be able to identify patients who are prone to tooth movement following tooth loss $[10,11]$. Thus the aim of the study is to evaluate the pathological changes associated with posterior tooth such as mobility, proclination, supraeruption.

\section{Materials and Methods}

\section{Study setting}

This study was a retrospective cross sectional study done in a university setting Saveetha Dental College, Chennai. Approval from ethical committee was obtained. Two examiners were involved in this study.

\section{Sampling}

The data was collected from the college software system,which maintains the records of patients with their intra oral and extra oral photographs (taken with consent of the patients), their demographic details, personal history, medical history and the Dental findings.

The study is a retrospective study. The data was collected over a period of nine months, from June 2019 to March 2020 the sample size of 419 was narrowed down, collected and data was verified with photographs obtained from the digital documentation.The inclusion criteria was all patients with American College of Prosthodontists-Prosthodontic diagnostic Index (ACP PDI) Class III, Multiple missing posterior teeth. The exclusion criteria was insufficient or incomplete case records and ACP PDI class I and II.

\section{Data collection}

Data of patients who had ACP PDI class III was collected from the record management system of the college. Data was entered in excel in a methodological manner and imported to SPSS.Incomplete data was excluded from study.

\section{Analysis}

IBM SPSS 23.0 software was used for data analysis. Independent variables include age, gender, ACP PDI Class III. Both descriptive and inferential statistics was done. Frequency distribution was done for age and gender. Chi square test was done to find the association and the level of significance was set at 0.05 .

\section{Results and Discussion}

The collected data was imported in SPSS software version 23.0 and the results were obtained using chi-square test.In this study only patients with ACP PDI Class III were included among which $50.1 \%$ male and $49.8 \%$ female patients. (Graph 2)

Among the patients who needed occlusal correction, 35.8\% male and $36.99 \%$ female patients needed generalised plane correction and $14.32 \%$ male and $12.89 \%$ female patients needed localised plane correction. There was no significant association between gender and plane correction.(P>0.05). (Graph 1)

However, in patients who needed localised plane correction, $14.32 \%$ had supra eruption, $12.41 \%$ had mobility, $0.24 \%$ had attrition and $0.24 \%$ had proclination of remaining teeth and in patients who needed generalised plane correction, $52.51 \%$ had supra eruption, $14.80 \%$ had mobility, $5.49 \%$ had attrition of remaining teeth for which the $\mathrm{P}$ value (0.000) was found to be statistically significant $(<0.05)$. Thus there is significant association between Occlusal correction and remaining teeth condition. (Graph 4)

In 18 to 30 years, $0.24 \%$ had mobility, $4.53 \%$ had supra eruption, $0.24 \%$ had proclination. In 31 to 50 years $12.41 \%$ had mobility, $28.40 \%$ had supra eruption, $1.43 \%$ had attrition. In 51 years and above $14.56 \%$ had mobility, $33.89 \%$ had supra eruption, $4.30 \%$ had attrition, this was statistically significant with $\mathrm{P}<0.05$. (Graph 5) 
Graph 1. The above depicted graph shows association between gender and patients requiring plane correction. $\mathrm{X}$-axis depicts gender and y-axis depicts count of patients who require plane correction. (green). There was no statistically significant difference in the plane correction between males and females. Pearson chi-square value is 0.395 with df 1 and $P$ value of 0.302(>0.05). Both male and female patients needed generalised plane correction.

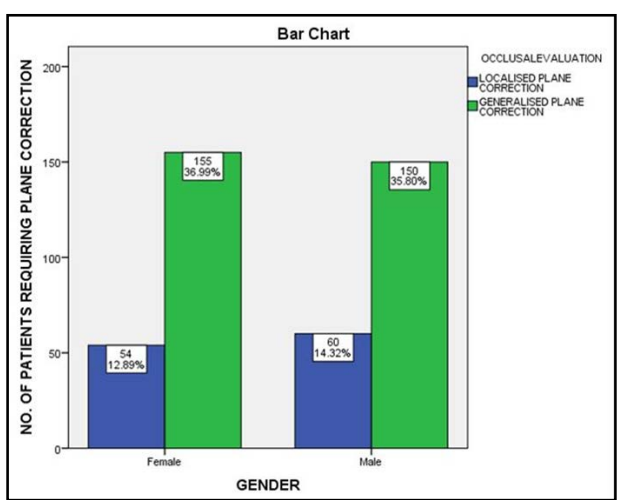

Graph 2. The above depicted graph shows association between gender and ACP PDI classification. X-axis depicts gender and $y$-axis depicts count of patients with ACP PDI class III. The above graph shows that $50.1 \%$ male and $49.8 \%$ female patients had class III of ACP PDI classification.

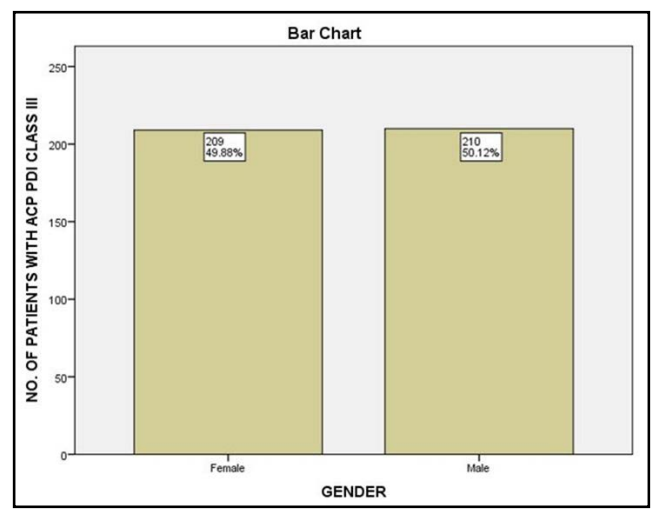

Graph 3. The above depicted graph shows association between gender and remaining teeth condition. X-axis depicts gender and y-axis depicts number of patients with mobility,supraeruption.proclination,attrition. Although supra eruption was the most common pathological change associated with posterior missing teeth in both male and female patients, there was no statistically significant difference between gender and remaining teeth condition. Pearson chi-square value is 2.590 with df 3 and $P$ value of $0.459(>0.05)$.

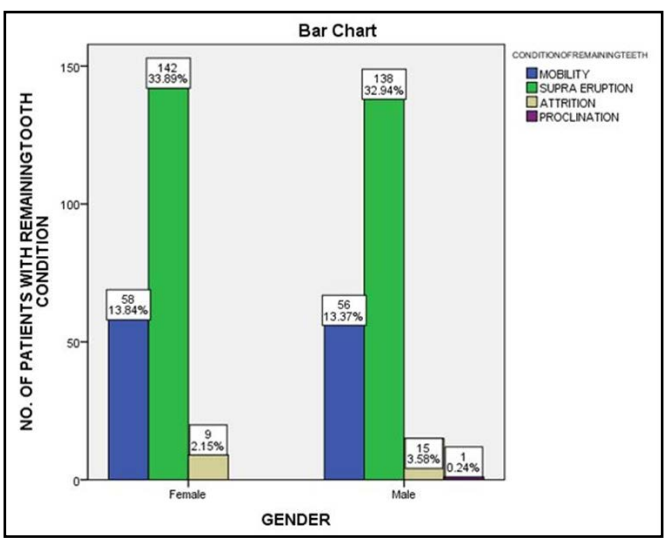

The positional stability of teeth opposing or adjacent to an edentulous space may not critically influence the oral functions of a patient unless occlusal interference occurs. However when prosthetic restoration of edentulous space becomes necessary difficulties may arise due to super eruption, mobility, tilting, rotation or attrition of dental arch. The present study shows supraeruption as most common change in antagonist tooth, this was similar to the result by Craddock et al [8]. In this study 114 patients out of 419 had mobility in the remaining teeth this is similar to Results by
Craddock Et al where the adjacent tooth or opposing teeth had statistically significant movement towards edentulous space [2].

Henry et all states that changes take place in adjacent teeth and in the remaining teeth like migration and attrition occur both are closely and interdentally [12]. A study by Witter et al states that occlusal wear and mobility were high in Dental arches with loss of posterior teeth [1]. With loss of posterior teeth that distribution of clenching forces also changes [13]. 
Graph 4. The above depicted graph shows association between occlusal evaluation and remaining teeth condition. $\mathrm{X}$-axis depicts occlusal evaluation and $y$-axis depicts count of patients with mobility,supraeruption.proclination,attrition. There was a statistically significant association between Occlusal correction and remaining teeth condition.Pearson chi-square value is 33.332 with df 3 and $P$ value of $0.000(<0.05)$. More number of patients with supra eruption needed plane correction than other factors.

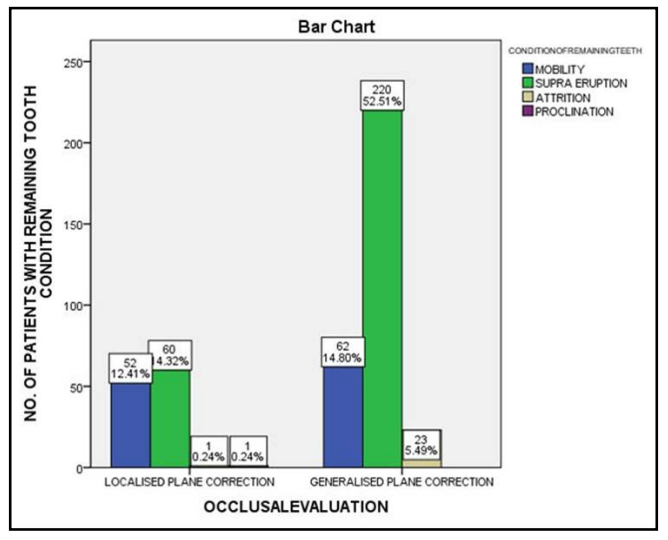

Graph 5. The above depicted graph shows association between age group and remaining teeth condition. $\mathrm{X}$-axis depicts age and $y$-axis depicts count of patients with mobility,supraeruption.proclination,attrition. There was a statistically significant association between Occlusal correction and remaining teeth condition. Pearson chi-square value is 30.287 with df 6 and $P$ value of $0.000(<0.05)$. Supra eruption was the most common change in the remaining tooth after loss of posterior teeth in all age groups.

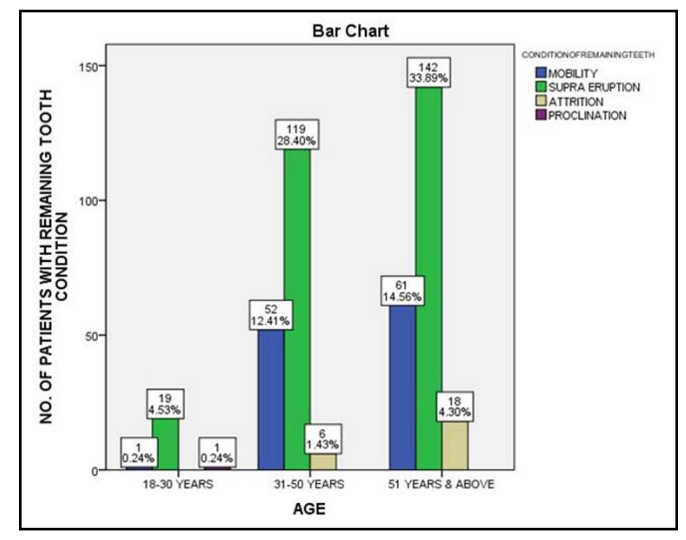

The present study indicates supra eruption of the opposing teeth as the common finding among both the genders and also to be increasing with the age factor indicating probability of extracting posterior teeth was more common for dental pain. The age group of $51 \mathrm{yrs}$ and above showing more supraeruption also indicates long term negligence for teeth replacement. When multiple teeth especially posteriors are missing there can be migration of opposing and adjacent teeth, this study indicates both are present and hence the indication of generalized occlusal correction. Previously conducted numerous clinical trials [14-21], A few review papers and questionnaire based studiesover the past 5 years [22-28]. The present study can be directed further into timing of extraction, reason for extraction, reason for negligence in replacement, clinical condition of remaining teeth, temporomandibular joint and functioning of gnathological system as whole.

\section{Conclusion}

From this study it can be concluded that ACP PDI class III condition creates spatial changes in the remaining natural teeth. Supra eruption as the most common changes to occur and such individuals required generalisedocclusal plane correction indicating its just not one tooth in the line for supraeruption correction but multiple teeth. This shows the long term negligence of patients in replacement of missing teeth, the importance of teeth replacement and its associated effect on other masticatory systems are lacking among the population studied.

\section{References}

[1]. Witter DJ, Creugers NH, Kreulen CM, De Haan AF. Occlusal stability in shortened dental arches. J. Dent. Res. 2001 Feb;80(2):432-6.

[2]. Craddock HL, Youngson CC. A study of the incidence of overeruption and occlusal interferences in unopposed posterior teeth. Br Dent J. 2004 Mar 27;196(6):341-8.Pubmed PMID: 15044991.

[3]. Heij DG, Opdebeeck H, van Steenberghe D, Kokich VG, Belser U, Quirynen M. Facial development, continuous tooth eruption, and mesial drift as compromising factors for implant placement. Int J Oral Maxillofac Implants. 2006 Nov-Dec;21(6):867-78.Pubmed PMID: 17190296.

[4]. Jacobson A. Dentists perception of risks for molars without antagonists. Am J Orthod DentofacialOrthop. 2002 Jan 1;121(1):101.

[5]. Mankani N, Chowdhary R, Mahoorkar S. Comparison of Stress Dissipation Pattern Underneath Complete Denture with Various Posterior Teeth form: An In Vitro Study. J Indian Prosthodont Soc. 2012 Sep;13(3):212-9. Pubmed PMID: 24431736.

[6]. DeVan MM. The nature of the partial denture foundation: suggestions for its preservation. J Prosthet Dent. 1952 Mar 1;2(2):210-8.

[7]. Shugars DA, BADER JD, PHILLIPS JR SW, WHITE BA, BRANTLEY CF. The consequences of not replacing a missing posterior tooth. J Am Dent Assoc. 2000 Sep 1;131(9):1317-23.

[8]. Craddock HL, Youngson CC, Manogue M, Blance A. Occlusal changes following posterior tooth loss in adults. Part 1: a study of clinical parameters 
associated with the extent and type of supraeruption in unopposed posterior teeth. J Prosthodont. 2007 Nov-Dec;16(6):485-94.Pubmed PMID: 17559530 .

[9]. Craddock HL, Youngson CC, Manogue M, Blance A. Occlusal changes following posterior tooth loss in adults. Part 2. Clinical parameters associated with movement of teeth adjacent to the site of posterior tooth loss. J Prosthodont. 2007 Nov-Dec;16(6):495-501.Pubmed PMID: 17672834.

[10]. Mesial Migration of Lower Molars in Relation to Facial Growth and Eruption of Teeth [Internet]. Vol. 115, American Journal of Orthodontics and Dentofacial Orthopedics. 1999. p. A1. Available from: http://dx.doi. org/10.1016/s0889-5406(99)70136-8

[11]. Aquilino SA, Shugars DA, Bader JD, White BA. Ten-year survival rates of teeth adjacent to treated and untreated posterior bounded edentulous spaces. J Prosthet Dent. 2001 May;85(5):455-60.Pubmed PMID: 11357071.

[12]. Beyron HL. Occlusal changes in adult dentition. J Am Dent Assoc. 1954 Jun 1;48(6):674-86.

[13]. Gibbs CH, Anusavice KJ, Young HM, Jones JS, Esquivel-Upshaw JF. Maximum clenching force of patients with moderate loss of posterior tooth support: a pilot study. J Prosthet Dent. 2002 Nov;88(5):498-502.Pubmed PMID: 12473999.

[14]. Jyothi S, Robin PK, Ganapathy D. Periodontal health status of three different groups wearing temporary partial denture. Res J Pharm Technol. 2017;10(12):4339-42.

[15]. Duraisamy R, Krishnan CS, Ramasubramanian H, Sampathkumar J, Mariappan S, NavarasampattiSivaprakasam A. Compatibility of Nonoriginal Abutments With Implants: Evaluation of Microgap at the Implant-Abutment Interface, With Original and Nonoriginal Abutments. Implant Dent. 2019 Jun;28(3):289-295.Pubmed PMID: 31124826.

[16]. Ganapathy D, Sathyamoorthy A, Ranganathan H, Murthykumar K. Effect of Resin Bonded Luting Agents Influencing Marginal Discrepancy in All Ceramic Complete Veneer Crowns. J ClinDiagn Res. 2016 Dec;10(12):ZC67ZC70.Pubmed PMID: 28209008.

[17]. Ranganathan H, Ganapathy DM, Jain AR. Cervical and Incisal Marginal
Discrepancy in Ceramic Laminate Veneering Materials: A SEM Analysis. ContempClin Dent. 2017 Apr-Jun;8(2):272-278.Pubmed PMID: 28839415.

[18]. Vijayalakshmi B, Ganapathy D. Medical management of cellulitis. Res J Pharm Technol. 2016;9(11):2067-70.

[19]. Ashok V, Nallaswamy D, Benazir Begum S, Nesappan T. Lip Bumper Prosthesis for an Acromegaly Patient: A Clinical Report. J Indian Prosthodont Soc. 2014 Dec;14(Suppl 1):279-82.Pubmed PMID: 26199531.

[20]. Venugopalan S, Ariga P, Aggarwal P, Viswanath A. Magnetically retained silicone facial prosthesis. Niger J ClinPract. 2014 Mar-Apr;17(2):260-4. Pubmed PMID: 24553044.

[21]. Ajay R, Suma K, Ali SA, Kumar Sivakumar JS, Rakshagan V, Devaki V, et al. Effect of Surface Modifications on the Retention of Cement-retained Implant Crowns under Fatigue Loads: An In vitro Study. J Pharm Bioallied Sci. 2017 Nov;9(Suppl 1):S154-S160.Pubmed PMID: 29284956.

[22]. Jain AR, Nallaswamy D, Ariga P, Ganapathy DM. Determination of correlation of width of maxillary anterior teeth using extraoral and intraoral factors in Indian population: A systematic review. World J Dent. 2018 Jan;9:68-75.

[23]. Selvan SR, Ganapathy D. Efficacy of fifth generation cephalosporins against methicillin-resistant Staphylococcus aureus-A review. Res J Pharm Technol. 2016;9(10):1815-8

[24]. Subasree S, Murthykumar K. Effect of Aloe Vera in Oral Health-A Review. Res J Pharm Technol. 2016;9(5):609-12.

[25]. Kannan A. Effect of Coated Surfaces influencing Screw Loosening in Implants: A Systematic Review and Meta-analysis. World. 2017 Nov;8(6):496502.

[26]. Ashok V, Suvitha S. Awareness of all ceramic restoration in rural population. Res J Pharm Technol. 2016;9(10):1691-3.

[27]. Kannan A, Venugopalan S. A systematic review on the effect of use of impregnated retraction cords on gingiva. Res J Pharm Technol. 2018;11(5):2121-6.

[28]. Basha FYS, Ganapathy D, Venugopalan S. Oral Hygiene Status among Pregnant Women. Res J Pharm Technol. 2018;11(7):3099-102. 